\title{
Agenesis of Ductus Venosus Presenting with Dilated Inferior Vena Cava with Favorable Outcome
}

\section{Omer Dai $^{1 *}$, Harun Egemen Tolunay ${ }^{1}$, Mehmet Murat Seval $^{1}$, Alper Kahraman $^{1}$, Korhan Kahraman $^{1}$, Acar Koç $^{1}$}

\begin{abstract}
The ductus venosus regulates the distribution of oxygen and placental nutrients by restricting the centralization of blood flow in fetal circulation. The ductus venosus is a small vein transmitting oxygen-rich blood from the umbilical vein to the fetal heart.. Increasing numbers of case reports are being published about ductus venosus agenesis with cardiac structural abnormalities, other malformations, chromosomal abnormalities, and stillbirth. Heart failure, hydrops and unexplained polyhydramnios could also be associated with ductus venosus agenesis. In the follow-up of fetuses with ductus venosus agenesis, care must be taken to examine for hydrops and heart failure. The agenesis of ductus venosus is often only found in fetuses by coincidentally. Herein we discuss the prenatal diagnosis of isolated agenesis of the ductus venosus presenting with a dilated inferior vena cava and without any disturbance of fetal hemodynamics and any other malformation. In conclusion a dilated inferior vena cava can be a sign of ductus venosus agenesia. Keywords: Agenesis of Ductus Venosus, Congenital Abnormalities, Obstetric Ultrasound
\end{abstract}

\section{Introduction}

Most maternal cardiac disease in Western There are profound differences in the cardiovascular system before and after birth. The source of oxygenation in the fetus is the placenta rather than the lungs. The oxygenated blood from the placenta returns to the fetus through the umbilical venous system. About $20 \%$ to $30 \%$ (this percentage decreases in a growth-restricted fetus) of umbilical venous blood bypasses the liver through a narrow trumpet-shaped vessel called the ductus venosus. It is commonly believed this is crucial for fetal development $(1,2)$. In healthy fetuses, the ductus venosus regulates the distribution of oxygen and placental nutrients by restricting the centralization of blood flow. It can be shown that fetal circulation follow two different routes, the via dextra and the via sinistra $(3,4)$. Deoxygenated blood from the superior vena cava (SVC) and the abdominal inferior vena cava (IVC) predominantly follows the via dextra (the right atrium, right ventricle, pulmonary trunk, ductus arteriosus, and descending aorta). On the other side, oxygenated umbilical blood is directed through the via sinistra (the ductus venosus, foramen ovale, left atrium, left ventricle, ascending aorta, isthmus aortae, and descending aorta) (5). The ductus venosus plays a key role in this separation. An increasing number of case reports are being published about ductus venosus agenesis with other malformations, chromosomal abnormalities, and in stillbirth (6-11), whereas the agenesis is often found almost coincidentally in fetuses. Herein we report on the prenatal diagnosis of isolated agenesis of the ductus venosus presenting with a dilated inferior vena cava and without any disturbance of fetal hemodynamics and any other malformation.

\section{Case Presentation}

A healthy 28-year-old woman, gravida 2, Parity 1 with one previous healthy child, was referred to our clinic for a routine obstetric ultrasound at 20 weeks' gestation. First trimester and second trimester aneuploidy screening test results showed no elevated risk for trisomy 21 and 13 . Maternal Alpha fetoprotein was within normal limits in 16 th week. The anatomical survey of the fetus was normal and no growth restriction was detected. The vena cava inferior was seen to be dilated and the ductus venosus could not be viewed during venous blood flow studies at the routine obstetric ultrasound scan at 20 weeks' gestation. The inferior vena cava and the venous flow velocity waveforms of the umbilical vein were normal with a constant flow. Fetal echocardiography did not show any anomalies. Although the screening tests were normal a cordocentesis was performed to eliminate any subtle anomalies in consideration of case reports indicating chromosomal anomalies accompanying ductus venosus agenesis. The patient's cordocentesis result was normal and hydrops fetalis were not detected in utero survey. On 38th week, she delivered a 3310 gram healthy boy without any abnormal phenotypic features. One year later after birth liver ultrasound was normal (Figures 1 and 2).

\section{Discussion}

The absence of the ductus venosus is a rare but well 


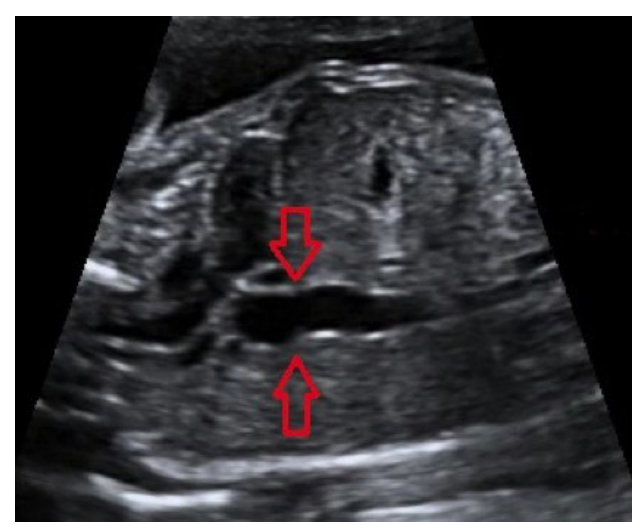

Figure 1. Sagittal view of fetal thorax-abdomen (Arrow: Dilated inferior vena cava)

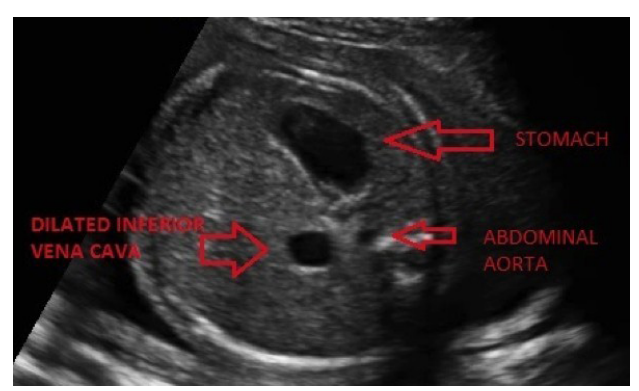

Figure 2. Horizontal section of fetal abdomen

described abnormality. Association with hydrops and structural or chromosomal abnormalities determine the prognosis of the condition.

Abnormalities of the umbilical vein within the fetal abdomen have in recent years been detected with prenatal sonography by the progress of doppler color flow techniques. In cases with ductus venosus agenesis two types of by-pass mechanism may be present, intrahepatic or extrahepatic. In the extrahepatic type, the umbilical vein can connect to the IVC connecting directly to the heart via the right atrium. In the intrahepatic type, the umbilical vein connects to the portal circulation so there is no connection between the portal system and the IVC (12). Furthermore, if there is an extrahepatic type of shunt, a dilated vena cava can be seen as in this case, owing to the continuing blood flow to the proximal aspects (direction) of the inferior vena cava. This is extrahepatic type, because the umbilical vein is opened directly to the inferior vena cava. In contrast to the present case, intrahepatic type has a more favorable prognosis. Berg et al. reported that none of the 13 fetuses without a liver bypass subsequently died, whereas in the group with a liver bypass, 20 of 29 survived (13). In the intrahepatic type, the umbilical vein is opened intrahepatic left portal vein.

However, some sonographic findings may indicate agenesis of the ductus venosus even in the cases that was not directly examined for this occurrence. Umbilical venous pulsations were shown to have disappeared in an animal study conducted on sheep by Kiserud et al. Loss of umbilical venous pulsations was thought to be caused by the reversed portocaval pressure gradient (14).

Agenesis of the ductus venosus could be related to cardiac structural abnormalities such as cardiomegaly and other congenital abnormalities. Heart failure, hydrops and unexplained polyhydramnios, could be associated with ductus venosus agenesis. In the follow-up of fetuses with ductus venosus agenesis, care must be taken to examine for hydrops and heart failure. Cases of Noonan syndrome, Turner syndrome and also Cystic higroma accompanying ductus venosus agenesis have been reported before $(6-8,15)$ (Table 1$)$.

\section{Conclusion}

In the present case, the diagnosis of absence of the ductus venosus was made at 20 weeks' gestation and no additional anatomical or chromosomal abnormalities were detected. A dilated inferior vena cava detected on routine ultrasound screening caused suspicions of ductus venosus agenesis. Subsequently a doppler flow work-up was performed and agenesis of the ductus venosus was revealed.

\section{Learning Points}

- A dilated inferior vena cava can be sign for ductus venosus agenesis.

- The association of congenital anomalies with ductus venosus agenesis should be kept in mind and fetal karyotyping should be considered in view of the important association with an abnormal karyotype, especially when other anomalies are present.

Table 1. Associations with Ductus Venosus Agenesis

- Cardiac structural abnormalities ( ASD (atrioventriculer septal defect), VSD (ventriculer septal defect), transposition of great vessels, pulmonary arterial abnormalities)

- Chromosomal abnormalities (Turner syndrome, Noonan syndrome, Trisomy 22, Cystic higroma and other sub chromosomal abnormalities)

- Hydrops and unexplained polyhydramnios

- $\quad$ Stillbirth

- Renal anomalies (hypoplasia, agenesis)

- $\quad$ Other malformations (cleft palate, hypospadias, mesomeli, single umbilical arter) 
- Careful serial ultrasonographic examinations should be performed particularly to screen cardiomegaly and hydrops fetalis.

- Without any coexisting anomalies, isolated ductus venosus agenesis is related to favorable postnatal outcomes.

\section{Ethical issues}

The local ethics committee approved the study.

\section{Conflict of interests}

The authors declare no conflict of interest in this study.

\section{Acknowledgments}

We would like to thank all of our colleagues who helped us in this study.

\section{References}

1. Kiserud T, Rasmussen S, Skulstad S. Blood flow and the degree of shunting through the ductus venosus in the human fetus. Am J Obstet Gynecol 2000;182:147-53.

2. Tchirikov M, Rybakowski C, Huneke B, Schroder HJ. Blood flow through the ductus venosus in singleton and multifetal pregnancies and in fetuses with intrauterine growth retardation. Am J Obstet Gynecol 1998;178:943-9

3. Barcroft J. Research on pre-natal life. Oxford: Blackwell Scientific Publications; 1946.

4. Hanson MA. Developmental physiology. Cambridge: Hanson MA, Kiserud T; 2001.

5. Kiserud T. Fetal venous circulation. Fetal Matern Med Rev 2003;14:57-95.

6. Bradley E, Kean L, Twining P, James D. Persistent right umbilical vein in a fetus with Noonan's syndrome: a case report. Ultrasound Obstet Gynecol 2001; 17:76-8.

7. Hasegawa T, Ogata T, Hasegawa Y, Honda M, Nagai T,
Fukushima Y, et al. Coarctation of the aorta and renal hypoplasia in a boy with Turner/Noonan surface anomalies and a 46,XY karyotype: a clinical model for the possible impairment of a putative lymphogenic gene(s) for Turner somatic stigmata. Hum Genet 1996; 97:564-7.

8. Contratti G, Banzi C, Ghi T, Perolo A, Pilu G, Visentin A. Absence of the ductus venosus: report of 10 new cases and review of the literature. Ultrasound Obstet Gynecol 2001; 18:605-9.

9. Hoppen T, Hofstaetter C, Plath H, Kau N, Bartmann P. Agenesis of the ductus venosus and its correlation to hydrops fetalis. J Perinat Med 2000;28:69-73.

10. Gembruch U, Baschat AA, Caliebe A, Gortner L. Prenatal diagnosis of ductus venosus agenesis: a report of two cases and review of the literature. Ultrasound Obstet Gynecol 1998; 11:185-9.

11. Volpe P, Marasini M, Caruso G, Lituania M, Marzullo A, Volpe $G$, et al. Prenatal diagnosis of ductus venosus agenesis and its association with cytogenetic/congenital anomalies. Prenat Diagn 2002; 22:995-1000.

12. Corbacioglu A, Aslan H, Dagdeviren H, Ceylan Y. Prenatal diagnosis of abnormal course of umbilical vein and ductus venosus agenesis: report of three cases. J Clin Ultrasound 2012; 40:590-3.

13. Berg C, Kamil D, Geipel A, Kohl T, Knopfle G, Hansmann $M$, et al. Absence of ductus venosus-importance of umbilical venous drainage site. Ultrasound Obstet Gynecol 2006; 28:275-81.

14. Kiserud T, Stratford L, Hanson MA. Umbilical flow distribution to the liver and the ductus venosus: an in vitro investigation of the fluid dynamic mechanisms in the fetal sheep. Am J Obstet Gynecol 1997; 177:86-90.

15. Digilio MC, Marino B, Picchio F, Prandstraller D, Toscano A, Giannotti A, et al. Noonan syndrome and aortic coarctation. Am J Obstet Gynecol 1998; 80:160-2.

Copyright $\odot 2014$ The Author(s); This is an open-access article distributed under the terms of the Creative Commons Attribution License (http://creativecommons.org/licenses/by/4.0), which permits unrestricted use, distribution, and reproduction in any medium, provided the original work is properly cited. 